\title{
Gender Differences in Social Anxiety Symptoms: A Novel Use of Two Self-Report Measures in a Finnish Sample
}

Sanna Kuusikko-Gauffin ${ }^{1}$, Rachel Pollock Wurman ${ }^{2}$, Marja-Leena Mattila ${ }^{1}$, Katja Jussila ${ }^{1}$, Hanna Ebeling ${ }^{1}$, Irma K. Moilanen ${ }^{1}$

1. Institute of Clinical Medicine, Department of Child Psychiatry, University and University Hospital of Oulu 2. Department of Psychiatry, Massachusetts General Hospital/ Harvard Medical School

$\square$ Corresponding author: Sanna Kuusikko-Gauffin, sanna.kuusikkogauffin@gmail.com Disclosures can be found in Additional Information at the end of the article

\section{Abstract}

Background: Social anxiety disorder (SAD) is characterized by a fear of humiliation and/or embarrassment in social situations, which may lead to significant avoidance and distress. A preponderance of research suggests that the prevalence of SAD is higher in females than in males and that gender differences of SAD varies cross-culturally. According to numerous studies, attention to the diagnosis and adequate assessment of anxiety disorders in primary care settings is lacking. A deficiency of easily administered well-validated diagnostic tools and limited time for thorough (i.e., structured clinical interview) evaluation may contribute to the above finding.

Procedure: Our principal aims were two-fold: 1) to focus on emergent gender differences in self- reported social anxiety (SA) symptoms, and 2) to evaluate newly translated Finnish versions of the Social Phobia and Anxiety Inventory (SPAI) and Brief Fear of Negative Evaluation Scale -Straightforward Items (BFNE-S) in a general Finnish parent sample $(\mathrm{N}=597)$.

Results and Conclusions: Results from our sample using the SPAI estimated that $6.7 \%$ of females and $5.0 \%$ of males met criteria for a probable diagnosis of SAD. Non socially-anxious females scored significantly higher than did their male counterparts on social interaction and focus of attention fears, whereas socially-anxious males scored higher than socially-anxious females on behavioural avoidance. The SPAI and BFNE-S are useful additions to Finnish screening tools to detect SA symptoms in adults.

Received 12/19/2012 Review began 12/19/2012 Published 12/20/2012

\section{(C) Copyright 2012}

Kuusikko-Gauffin et al. This is an open access article distributed under the terms of the Creative Commons Attribution License CCBY 3.0., which permits unrestricted use, distribution, and reproduction in any medium, provided the original author and source are credited.
Categories: Psychiatry, Psychology

Keywords: social phobia and anxiety inventory (spai), brief fear of negative evaluation scale straightforward items (bfne -s), adults, gender, social anxiety disorder, prevalence

\section{Introduction}

List of Abbreviations

AG Agoraphobia

ANOVA Analysis of Variance ANCOVA Analysis of Covariance

BFNE Brief Fear of Negative Evaluation Scale 
BFNE-S Brief Fear of Negative Evaluation Scale -Straightforward Items MANCOVA Multivariate Analysis of Covariance

SA Social Anxiety

SAD Social Anxiety Disorder

SP Social Phobia

SPAI Social Phobia and Anxiety Inventory

SPIN Social Phobia Inventory

Social anxiety disorder (SAD) is characterized with a fear of humiliation and/or embarrassment in social situations, which may lead to significant avoidance of and distress [1-2]. SAD is a chronic condition with an average duration of 20 years. The onset of SAD can be before the age of 10 with a typical age at onset during the mid to late teenage years; evidence suggests that males have an earlier age at onset than females [3-5]. The 12-month prevalence for SAD varies between cultures and nations, and seems to be higher in North and South America (e.g., Brazil, Chile, and USA) than in East Asian countries, such as China, Japan, Korea, or Taiwan (6.4-9.1\% vs. $0.2-0.8 \%$ ) [6]. In Europe, the 12-month prevalence rate for SAD is estimated below $1 \%$ [7]. The majority of SAD clinical studies of SAD indicate an over-presentation of male patients, particularly those with an early onset of SAD, high education levels, and high comorbidity rates $[6,8]$. In contrast, epidemiological studies reveal a strong trend in studies of community samples that women are significantly more likely to report SAD symptoms than are men. For example, in a recent epidemiological study by Xu and colleagues, the lifetime SAD prevalence in the USA for females was $5.7 \%$ and for males $4.2 \%$ [9]. These results indicate a gender discrepancy of a larger number of females who may experience social anxiety symptoms (and do not seek help) versus a larger clinical sample of males who are represented as clinical patients. Hence, empirically validated screening tools for SAD should be made available in a primary care setting to facilitate the apparent disconnect between gender, social anxiety (SA) symptoms, and clinical intervention. Furthermore, SA symptoms may vary (e.g., intensity of fear) between genders, and these differences should also be taken into account when screening for and treating SAD [9-10].

There is a growing body of research suggesting the efficacy of psychotherapeutic and pharmacological interventions in the treatment of SAD [11-12]. Despite encouraging evidence, SAD remains an often-times under-recognized and under-reported disorder, with studies indicating less than five percent of individuals with symptoms of social phobia (SP) currently seeking treatment [13-14]. Moreover, studies have shown that individuals with anxiety disorders seek medical attention more often than those without anxiety disorder; however, these patients tend to attribute their symptoms to physical causes (e.g., headaches, feeling tired, lightheaded, or sick to stomach) [15]. In general, research suggests that the diagnosis of anxiety disorders in primary care is lacking [16-18]. A shortage of easily administered wellvalidated diagnostic tools and limited time for thorough evaluation may contribute to the above finding.

In Finland, there is a paucity of self-report measures to evaluate SAD in adults. Ranta and colleagues [19] studied the validity of the 17-item Finnish version of the Social Phobia Inventory (SPIN) in a sample of 752 non-clinical adolescents ( $\mathrm{M}=14.6$ years) and found it to have good psychometric properties for screening and identifying adolescents with SAD. This study used higher cut-off scores (i.e., 24 vs. 19) than did the original study [20] to differentiate participants with and without SAD. Recently, Ranta and colleagues [21] have also examined the 
three item Mini-SPIN in Finnish adolescent population: The Finnish Mini-SPIN also demonstrated good psychometric properties differentiating adolescents with SAD from those without using the same cut-off scores as the original Mini-SPIN study conducted in the UK. In addition to the SPIN and Mini-SPIN, it is of great clinical utility and research import to utilize more internationally established social anxiety questionnaires as tools in the Finnish diagnostic arsenal for adult psychiatry and primary care.

One of the most well-established and empirically sound screening instruments for examining SAD in adults is the 45-item Social Phobia and Anxiety Inventory (SPAI) [22], which includes two scales derived directly from the DSM criteria for: 1) SAD and 2) panic disorder. The SPAI has been translated into many languages (e.g., Icelandic, Canadian French, Dutch, Portuguese, Spanish, and Swedish), and its psychometric properties are excellent [22-31]. Another screening instrument, specifically developed to assess an individual's perceived fear of negative evaluation, is a shorter, 12-item Brief Fear of Negative Evaluation Scale (BFNE) [32]. The BFNE also has been translated into many languages (e.g., Chinese, Farsi, Japanese, German, Greek, Spanish, and Turkish) and has demonstrated strong psychometric properties. The eight-item straightforward coded subscale of the BFNE (BFNE-S) has shown better reliability and validity than the four-item reverse coded subscale [33-45].

The aim of this study was to evaluate gender differences of SA symptoms in a general Finnish parent sample using the newly translated Finnish versions of the SPAI and BFNE-S.

\section{Materials And Methods}

\section{Procedure}

The current data were collected in 2006 as a part of larger study regarding SA in a Finnish sample of community children (age range: 7.3- 16.5 years) [46]. Participants were randomly recruited via all mainstream schools in the city of Oulu, Finland; pupils were asked to bring the study materials (letter of consent, SPAI, and BFNE-S) home to their parents. After consenting to participation, parents completed the SPAI and BFNE-S questionnaires and returned all study forms in a sealed envelope to the school with their child. This study was approved by the Ethics Committee of the Northern Ostrobothnia Hospital District.

\section{Participants}

Six hundred and twenty-one adults consented to participate in the study. In 24 cases, there was more missing data in the SPAI questionnaire than allowed for based on the SPAI manual [22] or more than one missing item in BFNE-S. Thus, the final sample consisted of 597 participants (368 females, 229 males). Demographic information is reported in Figure 1.

\begin{tabular}{|c|c|c|}
\hline Variable & Males $(\mathrm{N}=229)$ & Females $(\mathrm{N}=368)$ \\
\hline$M$ age in years $(S D, \text { range })^{*} \dagger$ & $44.8(5.5,30.5-64.0)$ & $41.7(5.6,26.3-59.0)$ \\
\hline \multicolumn{3}{|l|}{ Education } \\
\hline Lower secondary & $9.3 \%$ & $8.6 \%$ \\
\hline Upper secondary & $40.9 \%$ & $47.9 \%$ \\
\hline Tertiary & $24.3 \%$ & $26.7 \%$ \\
\hline \multicolumn{3}{|l|}{ Marital status* +} \\
\hline Married/Common law & $93.3 \%$ & $73 \%$ \\
\hline Single/Divorced & $6.7 \%^{a}$ & $27 \%$ \\
\hline
\end{tabular}

${ }^{*} t p<.001$, two-tailed. ${ }^{a} 0.8 \%$ of men were widows 


\section{FIGURE 1: Demographic Information}

${ }^{*}<.001$, two-tailed. a0.8\% of men were widows

\section{Measures}

The SPAI: The SPAI [22] consists of 45 primary items rated on a seven-point Likert-type scale (0 $=$ Never to 6 = Always). The SPAI can be divided into 1) the Difference score [i.e., social phobia (SP) score, minus the Agoraphobia (AG) score, 32 items] and 2) the AG score (13 items). In this study, we focused on the Difference score; scores range from 0 to 192 . The original cut-off score for Probable SP, according to US samples reported in the SPAI manual, equals any Difference score greater than or equal to 80. According to the SPAI manual, there are also different cut-off scores indicating the likelihood of SP: Unlikely SP (Difference score < 34), Possible mild SP (Difference score $=34-59$ ), and Possible SP (Difference score $=60-79$ ) [22]. The SPAI has five subscales: 1) Social Interaction (11 items), 2) Somatic and Cognitive (7 items), 3) Group Interaction (7 items), 4) Avoidance (8 items), and 5) Focus of Attention (5 items).

We were interested in gender differences in the frequency and severity of SA symptoms according to certain target social situations, as an individual's symptoms may be triggered in a variety of settings or situations. For example, significant social anxiety may emerge only when an individual is around strangers, authority figures, opposite sex, or people in general. The original SPAI subscales sums the presence of SA symptoms, including all four possible situations listed above, without differentiating them. In order to best examine these differences, we formed separate sum scores of 17 SPAI items, which consisted of four possible social situations (e.g., "I feel anxious when in a small gathering with; I feel anxious when speaking in front of: 1) strangers, 2) authority figures, 3) opposite sex, or 4) people in general." We named these four new subscales: Strangers; Authority; Opposite sex; and Generalized SA, which were rated identically to the other subscales based on the SPAI manual.

In the current study, the SPAI was translated from English into Finnish by two clinical psychologists and back-translated into English by an official translator; English versions were compared by a native English-speaking clinical psychologist. Additional back-translation for the SPAI was conducted by an official translator of Multi-Health System, Inc. Internal consistency for our sample was measured via Cronbach's Alpha: Internal consistency was excellent for the SPAI difference score $(\alpha=.99)$ as well as its five subscales $(\alpha=.94$ to $\alpha=.98)$. For the newly formed SPAI subscales (i.e., Strangers, Authority, Opposite sex, and People in general), internal consistency was also excellent ( $\alpha=.95$ to $\alpha=.96)$.

The BFNE-S: The BFNE-S is an eight item scale to evaluate symptoms of anxiety-related perceived negative evaluation (e.g., "I am afraid others will not approve of me;" I often worry that I will say or do the wrong things.") [32]. Items are rated on a five-point Likert type scale (1 = Not at all to $5=$ Extremely); BFNE-S scores range from 8 to 40 . In our study sample, the internal consistency was good for the BFNE-S $(\alpha=.88)$.

\section{Statistical methods}

All statistical analyses were performed using the SPSS 19.0 Statistical Software Program for the Macintosh. We completed heuristic analyses to consider appropriate covariates (e.g., education, marital status, and age). We employed parametric tests, such as analysis of variance (ANOVA), analysis of covariance (ANCOVA), and multivariate analysis of covariance (MANCOVA).

Internal consistency was tested using Cronbach's Alpha $(\alpha)$. Effect size was evaluated using the 
Eta-squared $\left(\eta_{p}{ }^{2}\right)$ statistic: According to Cohen [47], $\eta_{p}{ }^{2}=0.01$ is considered a small effect, $\eta_{p}{ }^{2}=0.06$ a medium effect, and $\eta_{p}{ }^{2}=0.14$ a large effect. All tests of statistical significance are reported as two-tailed.

\section{Results}

\section{Heuristic analyses}

There were no statistically significant gender differences on education level: $\mathrm{t}(493)=0.3, \mathrm{p}=\mathrm{ns}$ (see Figure 2). In our sample, there were statistically significantly more single/divorced females (living with their children) than males (living with their children) $\left(\chi^{2}=29.3, \mathrm{df}=1, \mathrm{p}<.001\right.$ ). There were no significant differences between single/divorced males and single/divorced females on any employed measures. Of note, married/common-law married females scored higher than their male counterparts on the SPAI Difference score, as well as the SPAI subscales of Social interaction, Somatic, and Cognitive, Focus of attention, Strangers, Authority, and Opposite sex. There were no statistically significant differences among females between marital status groups on any outcome measures; however, married/common law married males scored significantly higher than single/divorced males on the SPAI subscale of Avoidance: $\mathrm{t}(493)=2.4, \mathrm{p}<.05$. Thus, we added marital status as a covariate to all further analyses involving the SPAI. Marital status was not related to BFNE-S scores.

Males in our sample were also older than females: $\mathrm{t}(384)=3.46, \mathrm{p}<.001$. Due to a data collection error, however, we did not collect the age of all males, which prevented us from adding age to the statistical models. Of note, males with missing age data $(n=185)$ did not differ significantly from control males where age was collected $(n=44)$ on any variables of interest. We examined age by splitting participants into two age groups within gender by median age. There were no statistically significant differences between younger participants compared to older participants within or between gender groups on any outcome variables.

\section{Association between SPAI and BFNE-S}

We conducted partial correlations, controlling for marital status to examine the association between SPAI and BFNE-S. There were strong relationships between the SPAI Difference score and the BFNE-S $(r=.46, p<.01)$ and between SPAI subscales and BFNE-S ( $r$ range .30 to $.48 ; \mathrm{p}<$ .001 , for all).

\section{Descriptive characteristics of the SPAI and BFNE-S by gender}

We used ANCOVA, controlling for marital status, to study gender differences on SPAI Difference scores, females scored statistically significantly higher than did males (See Table 1). In order to examine the mean scores of the SPAI subscales, we conducted MANCOVA with gender as the fixed factor and SPAI scores as the outcome variable, controlling for marital status. The main effect of gender was significant $\left(F(9,453)=9.5\right.$, Wilks' $\Lambda=.88, \eta_{\mathrm{p}}^{2}=.11, \mathrm{p}<$ .001) with females scoring higher than males on all SPAI subscales, with the exception of Avoidance.

Further, results of an ANOVA examining gender differences on the BFNE-S indicated that females scored higher than males. Findings regarding SPAI and BFNE-S mean scores between genders are reported in Table 1. 


\section{Cureus}

\begin{tabular}{|c|c|c|c|c|}
\hline & Females & Males & $F(d f=1)$ & $F(d f=1) \eta_{p}^{2}$ \\
\hline SPAI & M(std.E) & M(std.E) & & \\
\hline Difference score & $36.4(1.6)$ & $29.6(2.3)$ & $7.4^{\star \star}$ & .02 \\
\hline Social interaction & $57.7(3.0)$ & $44.3(3.0)$ & $11.5^{\star} \dagger$ & .02 \\
\hline Somatic and cognitive & $24.1(1.2)$ & $19.0(1.5)$ & $6.5^{\star \star}$ & .01 \\
\hline Group interaction & $17.9(0.9)$ & $14.9(1.1)$ & $4.6^{\star}$ & .01 \\
\hline Avoidance & $6.0(0.5)$ & $6.8(0.6)$ & 1.0 & .00 \\
\hline Focus of attention & $14.1(0.6)$ & $10.7(0.7)$ & $12.7^{\star} \dagger$ & .03 \\
\hline Strangers & $19.3(0.8)$ & $15.5(1.1)$ & $7.2^{\star \star}$ & .02 \\
\hline Authority & $22.5(1.0)$ & $17.0(1.2)$ & $12.5^{\star} \dagger$ & .03 \\
\hline Opposite sex & $18.5(0.8)$ & $14.8(1.1)$ & $7.1^{\star \star}$ & .02 \\
\hline People in general & $17.4(0.8)$ & $14.6(1.0)$ & $4.5^{\star}$ & .01 \\
\hline BFNE-S & $12.6(4.7)$ & $11.7(3.9)$ & $5.7^{*}$ & .01 \\
\hline
\end{tabular}

TABLE 1: Means of the SPAI Subscale (controlling for Marital Status) and BFNE-S scores

${ }^{*} p<.05,{ }^{* *} p<.01,{ }^{*} p p<.001$, two-tailed.

\section{The SPAl cut-off score distribution}

$6.7 \%$ of females $(n=23)$ and $5.0 \%$ of males $(n=11)$ scored on or above the Probable SP cut-off score defined by the SPAI. The distribution of the SPAI Difference score is presented in Table 2. 


\section{Cureus}

\begin{tabular}{|c|c|c|c|}
\hline SPAI SP Likelinood & Females \%, M Score (sd) & Males \%, M Score (sd) & $X^{2}(d f=1)$ \\
\hline Probable SP (score? 80) & $6.7,95.3(15.8)$ & $5.0,95.8(25.0)$ & $8.2^{\star \star \star}$ \\
\hline Possible SP (score 60-79) & $10.2,69.1(5.9)$ & $5.9,69.5(6.3)$ & $64.7^{\star} \dagger$ \\
\hline Possible Mild SP (score 34-59) & $30.2,45.2(7.8)$ & $24.4,45.4(6.6)$ & 3.3 \\
\hline Unlikely SP (score < 34) & $52.8,16.2(10.2)$ & $64.7,14.3(10.6)$ & .7 \\
\hline
\end{tabular}

\section{TABLE 2: The SPAI Difference Score Distribution.}

${ }^{* *} p<.01,{ }^{*} p p<.001$, two-tailed.

\section{SPAI subscale scores in each SPAI SP likelihood groups by gender}

We examined whether SA symptoms vary between genders in different SPAI SP likelihood groups. We, therefore, conducted separate MANCOVAs (SPAI subscales $\mathrm{x}$ gender, controlling for marital status) for each SP likelihood groups (i.e., Probable SP, Possible SP, Possible mild SP, Unlikely SP). In the Unlikely SP group, there was a main effect of gender (Wilks' $\Lambda=.83, F(9$, $253)=5.7, \mathrm{n}_{\mathrm{p}}^{2}=.12, \mathrm{p}<.001$; females scored statistically significantly higher than males on the SPAI subscales-- Social interaction, Focus of attention, and Authority $\left(F(1)=6.9, \eta_{p}{ }^{2}=.03, p<\right.$ $\left..01 ; \mathrm{F}(1)=8.7, \mathrm{n}_{\mathrm{p}}{ }^{2}=.03, \mathrm{p}<.01 ; \mathrm{F}(1)=6.8, \mathrm{\eta}_{\mathrm{p}}^{2}=.03, \mathrm{p}<.01\right)$. Males, however, scored higher than females on the SPAI subscale of Avoidance $\left(F(1)=12.3, \eta_{\mathrm{p}}{ }^{2}=.05, \mathrm{p}<.001\right)$.

There were no significant gender effects for Possible Mild, Possible, or Probable SP (Wilks' $\Lambda=$ $.92, \mathrm{~F}(5)=2.2, \mathrm{\eta}_{\mathrm{p}}{ }^{2}=.08, \mathrm{p}=.055 ;$ Wilks' $^{\prime}=.95, \mathrm{~F}(5)=.03, \mathrm{\eta}_{\mathrm{p}}{ }^{2}=.05, \mathrm{p}=\mathrm{ns} ;$ Wilks' $\Lambda=.70, \mathrm{~F}(5)=$ $\left.1.6, \eta_{\mathrm{p}}{ }^{2}=.31, \mathrm{p}=\mathrm{ns}\right)$. Between-subjects tests, however, revealed a gender difference on the SPAI subscale of Avoidance; again, males scored significantly higher than females on groups of Possible Mild and Probable SP $\left(F(1)=5.2, \eta_{\mathrm{p}}^{2}=.04, \mathrm{p}<.05 ; \mathrm{F}(1)=5.2, \eta_{\mathrm{p}}{ }^{2}=.19, \mathrm{p}<.05\right)$.

\section{BFNE-S scores in each SPAI SP likelihood groups by gender}

We conducted ANOVA to study the BFNE-S score distribution between SPAI SP likelihood groups (fixed factors: gender, SP likelihood group). As expected, there was a significant main effect of SP likelihood group, with an increased BFNE-S score associated with an increased probability of having SP (based on the SPAI) $\left(F(555)=39.9, \mathrm{p}<.001, \mathrm{n}_{\mathrm{p}}{ }^{2}=.18\right.$ ) (Figure 2). The main effect of gender was non-significant. A significant interaction between gender and SP likelihood groups emerged: $\mathrm{F}(555)=3.1, \mathrm{\eta}_{\mathrm{p}}{ }^{2}=.02, \mathrm{p}<.05$. Males scored higher than females in the Possible SP group, whereas females scored higher than males in all other categories. 


\section{Cureus}

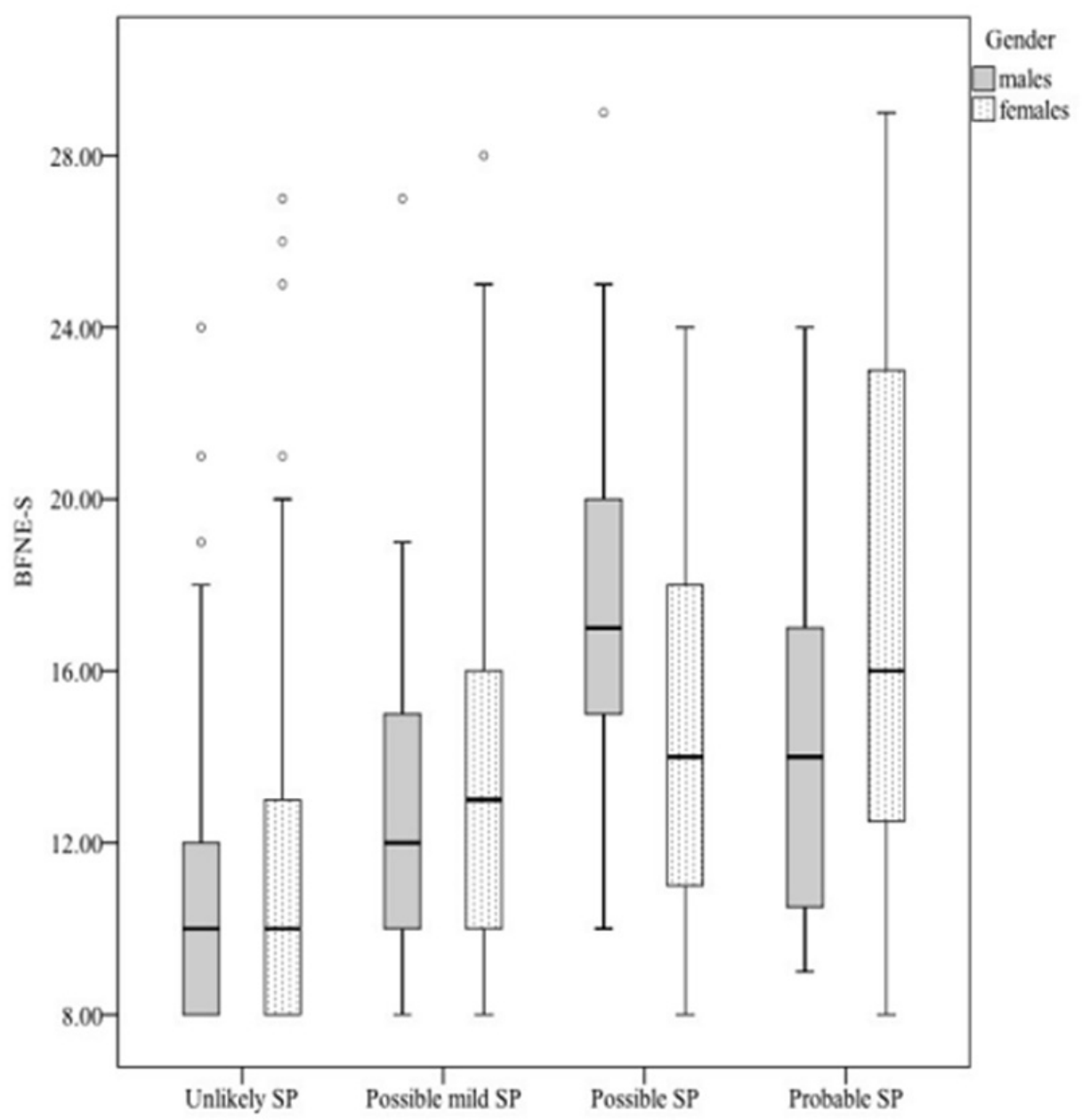

FIGURE 2: The BFNE-S Score Distribution Between SPAI Likelihood Groups by Gender

\section{Discussion}

The aim of our study was to examine gender differences in SA symptoms with the newlytranslated Finnish versions of the SPAI and BFNE-S in an adult Finnish sample.

In sum, our analyses yielded the following results: 1 ) females scored statistically significantly higher than males on all SPAI and BFNE-S scales, with exception of the SPAI avoidance subscale; 2) non-socially-anxious females (based on SPAI SP likelihood groups) scored significantly higher than their male counterparts on fear of social interaction, focus of attention, and social anxiety in the presence of authority figures. However, non-sociallyanxious as well as socially-anxious males scored significantly higher than their female counterparts on SA symptoms of behavioural avoidance; 3) the self-reported severity of overall SA symptoms and other SA subtype symptoms, with exception of behavioural avoidance, were similar in socially-anxious males and socially-anxious females; 4 ) the prevalence of probable SP in our study was $6.7 \%$ for females and $5.0 \%$ for males; 5 ) data revealed that the Finnish SPAI has excellent internal consistency, indicating that the original factor structure of the SPAI is consistent in the Finnish version; 6) the Finnish BFNE-S also demonstrated good internal consistency, and therefore, may also be considered a novel and useful addition to the Finnish 
arsenal to measure social anxiety symptoms.

Our results are consistent with the findings of previous studies and iterate the need to focus on different subtypes of SA symptoms between genders [22-24, 30]. Consistent with studies conducted in Spain [48] and the USA [35], we detected a statistically significant gender difference for the fear of negative evaluation; however, these results were contrary to findings by Koydemir and Demir in Turkey [37, 49]. Our findings are similar to previous research suggesting that behavioural avoidance may be a more common SA symptom in males than in females [29, 50]. Interestingly, despite an increase in behavioral avoidance for males, as noted earlier, males are more likely, in general, to seek clinical intervention for their SA symptoms.

In our sample, married/common-law married females scored statistically significantly higher than their male counterparts on the SPAI overall, somatic and cognitive SA symptoms, symptoms emerging in social interactions, SA concerns with being the focus of attention, and SA symptoms presenting during interactions with strangers, authority figures, and members of the opposite sex. Married/common-law married males scored also significantly higher than single/divorced males on behavioural avoidance symptoms of SA. Marital status was unrelated to the fear of negative evaluation. Our findings suggest that marital status effects experienced SA symptoms, especially in Finnish females. We did not measure marital satisfaction in our study; thus, we are unable to determine whether distress in the marriage was associated with an increase in experienced SA symptoms. In a recent study by Cairney and colleagues (2007), the authors found no significant relationships between SAD and gender or marital status in older Canadian adults (over 55 years of old, $\mathrm{N}=12,792$ ) [51].

In our sample, Finnish adults scored lower, in general, than participants from most other international studies conducted with the SPAI or BFNE-S (Tables 3, 4). These differences may be in part explained by age variance, for example, participants in our study tended to be older than most of the samples collected in previous studies. Many previous study results were based on data from undergraduate students. The BFNE-S mean in our sample (Table 4) was most comparable with the community sample studied by Weeks and colleagues [43], which also included adults (M age 33.1). Fear of negative evaluation may decrease with age in a Finnish general population. Most importantly, however, these differences imply the role of culture in the report of social anxiety symptoms, as the actual SAD prevalence rates reported by other European countries is similar, but considerably lower than rates reported in the USA [7, 9]. 


\section{Cureus}

\begin{tabular}{|c|c|c|c|c|c|c|}
\hline Study Origin & Participants & $\mathbf{N}$ & $\begin{array}{l}\text { M } \\
\text { Age }\end{array}$ & SPAI Difference Score M Males & Females & All \\
\hline \multirow[t]{2}{*}{ Finland $^{*}$} & General community sample & 597 & 42.1 & 29.6 & 36.4 & 33.2 \\
\hline & Adults with Probable SP & 34 & 40.5 & 95.8 & 95.3 & 95.5 \\
\hline \multirow[t]{2}{*}{ Netherlands [27] } & Community adults & 65 & 31.4 & 73.3a & $76.7 a$ & 41.39 \\
\hline & SAD patients & 92 & 32.5 & 73.3a & $76.7 a$ & 99.10 \\
\hline \multirow[t]{2}{*}{ USA [22] } & College students without SAD & 124 & $\mathrm{n} / \mathrm{a}$ & $\mathrm{n} / \mathrm{a}$ & $\mathrm{n} / \mathrm{a}$ & 32.7 \\
\hline & College students with SAD & 58 & $\mathrm{n} / \mathrm{a}$ & $\mathrm{n} / \mathrm{a}$ & $\mathrm{n} / \mathrm{a}$ & 72.2 \\
\hline \multirow[t]{2}{*}{ Spain [23] } & Nonclinical sample & 198 & 34.2 & 41.6 & 46.6 & 44.9 \\
\hline & SAD patients & 72 & 27.0 & 102.5 & 99.9 & 100.8 \\
\hline Brazil [24] & University students & 213 & 23.0 & 48.5 & 50.5 & 49.6 \\
\hline Australia [25] & SAD patients & 73 & 31.3 & $\mathrm{n} / \mathrm{a}$ & $\mathrm{n} / \mathrm{a}$ & 110.6 \\
\hline Canada [28] & SAD patients & 25 & 33.8 & $\mathrm{n} / \mathrm{a}$ & $\mathrm{n} / \mathrm{a}$ & 100.5 \\
\hline USA [30] & Community adults with SAD & 61 & 35.3 & $\mathrm{n} / \mathrm{a}$ & $\mathrm{n} / \mathrm{a}$ & 103.3 \\
\hline USA [52] & GSP patients & 20 & 30.4 & $n / a$ & $n / a$ & 96.5 \\
\hline
\end{tabular}

\section{TABLE 3: The SPAI Difference Score Distribution}

${ }^{*}$ Current study, $\mathrm{n} / \mathrm{a}=$ information not available, $\mathrm{a}=$ Community and clinical patient samples combined while males and females scores were reported separately, GSP = generalized social phobia without avoidant personality disorder. 


\section{Cureus}

\begin{tabular}{|c|c|c|c|c|}
\hline Study Origin & Participants & Study $\mathbf{N}$ & $M$ age & BFNE-S M score \\
\hline \multirow[t]{2}{*}{ Finland* ${ }^{*}$} & General community sample & 597 & 42.1 & 12.3 \\
\hline & Adults with Probable SP & 34 & 40.5 & 16.4 \\
\hline Canada [33] & SAD patients & 121 & $\mathrm{n} / \mathrm{a}$ & 27.0 \\
\hline \multirow[t]{2}{*}{ Spain [48] } & Student sample & 527 & 21.7 & 21.4 \\
\hline & SAD patients & 122 & 24.1 & 26.6 \\
\hline \multirow[t]{2}{*}{ USA [43] } & Non-anxious community sample & 32 & 33.1 & 12.5 \\
\hline & SAD patients & 165 & 32.4 & 30.6 \\
\hline USA [38] & Undergraduates & 1049 & $\mathrm{n} / \mathrm{a}$ & 20.0 \\
\hline
\end{tabular}

\section{TABLE 4: Literature Review of SPAI Difference Scores}

Note: *current study, $\mathrm{n} / \mathrm{a}=$ information not available.

The female-male ratio of probable SP diagnoses in our sample was similar to that found in previous studies conducted in Finland, but the SP prevalence in our study was higher than these other studies [53-54]. Ranta and colleagues [53], for example, estimated a 12-month prevalence of $3.2 \%$ for social phobia and $4.6 \%$ prevalence for sub-clinical social phobia among 12 to 17 year old adolescents using the SPIN and confirmed SAD diagnoses with a semistructured interview. The authors also suggested that the prevalence of SAD rose as age increased (from 12 to 17 years), thus approaching our adult population estimate, and including the ages of peak pubertal changes, known correlates with SA symptoms. Contrary to our study and the Ranta, et al. study [53], Pirkola and colleagues [54] reported a 12-month prevalence of $1 \%$ for social phobia in Finnish adults $(\mathrm{M}$ age $=45.3$ years) using the Munich version of the Composite International Diagnostic Interview [55]. The difference between prevalence rates of SAD estimated in Finland may be explained with different methodologies used in studies. Specifically, the participation rate of socially anxious individuals may be higher when using self-report surveys than in studies requiring direct interviews and clinical examinations. Also, our sample consisted exclusively of parents, where as Ranta's [53] sample were adolescents and Pirkola's [54] sample included adults with and without children.

There were several limitations in our study: First, the prevalence of SAD in our sample, needs to be interpreted cautiously, as we did not confirm SAD scores with clinical diagnostic tools, such as structured diagnostic interviews (The Structured Clinical Interview for DSM-IV, The Anxiety Disorders Interview Schedule for DSM-IV) or diagnostic criteria (i.e., DSM-IV, ICD-10). We employed two SAD self-report measures; individual high on fear of negative evaluation may in fact report their symptoms more accurately via self-report when compared with diagnostic interviews, as the interpersonal interview situation itself may trigger a participant's concern with the desire for approval and increase his/her distress regarding negative evaluation during the interview setting [56-62]. Second, although the focus of our study was specifically to assess subjective self-reported social anxiety symptoms using the SPAI and BFNE-S, future studies will include multi-method assessment (e.g., self-report and structured clinical interview), in order to more comprehensively assess the presence of SA symptoms and clinical diagnoses and in order to minimize the potential for self-report biases. Also, in previous studies [63], number of siblings in families was significantly associated with parental stress. We did not collect data 
on current family size. Thus, in future studies it would be important to gather information regarding current family size and number of siblings to investigate whether this association is consistent when looking at social anxiety symptoms and to determine if statistical models should include these data. Third, our data did not include age information for all male participants due to data collection error, thus preventing us from including all male participants' age in the statistical models. Finally, our adult sample was derived from general parent population, that is, all of our adult participants had children; thus, our sample may not be fully representative of a general community sample.

\section{Conclusions}

In conclusion, females scored statistically significantly higher than males on all SPAI and BFNE-S scales, with exception of the SPAI avoidance subscale. Non socially-anxious females seem to be more prone to fear social interaction and being the focus of attention than non socially-anxious males. For socially-anxious males, behavioural avoidance may be a more prominent symptom than for socially-anxious females. Finnish versions of the SPAI and BFNE$\mathrm{S}$ are good additions to Finnish screening tools to detect SA in adults.

\section{Additional Information}

\section{Disclosures}

Human subjects: Consent was obtained by all participants in this study. The Ethics Committee of the Northern Ostrobothnia Hospital District issued approval N/A. Animal subjects: All authors have confirmed that this study did not involve animal subjects or tissue. Conflicts of interest: In compliance with the ICMJE uniform disclosure form, all authors declare the following: Payment/services info: The research was supported by The Alma and K. A. Snellman Foundation, Oulu, Finland (PI: S. Kuusikko-Gauffin), Child Psychiatric Research Foundation, Finland (PI: S. Kuusikko-Gauffin), Emil Aaltonen Foundation, Finland (PI: H. Ebeling, S. Kuusikko-Gauffin), Sigrid Juselius Foundation, Finland (PI: I Moilanen). Financial relationships: All authors have declared that they have no financial relationships at present or within the previous three years with any organizations that might have an interest in the submitted work. Other relationships: All authors have declared that there are no other relationships or activities that could appear to have influenced the submitted work.

\section{Acknowledgements}

Authors' Contributions: SKG participated in the design of the study, carried out the data collection, performed statistical analyses, and wrote the manuscript. RAPW participated in the design of the study, helped with statistical analyses, contributed to writing the manuscript and completed the language check/editorial review for the manuscript. M-LM, HE, KJ and IM helped to draft the manuscript. SKG, HE, IM also received funding for the study. All authors read and approved the final manuscript. Acknowledgements: We want to thank the participants of the study.

\section{References}

1. American Psychiatric Association (APA). Diagnostic Statistical Manual of Mental Disorders . American Psychiatric Association. Washington, DC; 2000.

2. World Health Organization (WHO): ICD-10 Classification of Mental and Behavioural Disorders: Diagnostic Criteria for Research. World Health Organization (WHO), Geneva, Switzerland; 1993.

3. Manuzza S, Fyer AJ, Liebowitz MR, Klein DF: Delineating the boundaries of social phobia: Its relationship to panic disorder and agoraphobia. J Anx Disord. 1990, 4:41-59.

4. Wittchen HU, Beloch E: The impact of social phobia on quality of life . Int Clin Psychopharmacol . 1996, 11:15-23. 
5. Schneier FR, Spitzer RL, Gibbon M, Fyer AJ, Liebowitz MR, Weisman MM: Social Phobia. Comorbidity in an epidemiological sample. Arch Gen Psychiatry . 1992, 49:282-88.

6. Hofmann SG, Asnaani A, Hinton DE: Cultural aspects in social anxiety and social anxiety disorder. Depress Anxiety. 2010, 27:1117-27.

7. Alonso J, Angermeyer MC, Bernert S, Bruffaerts R, Brugha TS, Bryson H, et al.: Prevalence of mental disorders in Europe: results from the European Study of the Epidemiology of Mental Disorders (ESEMeD) project. Acta Psychiatr Scand . 2004, 109:21-27.

8. de Menezes GB, Fontenelle LF, Versiani M: Trans-cultural aspects of social anxiety disorder and related conditions: a Brazilian case series and a review of international clinical studies. J Bras Psiquiatr. 2006, 55:196-200.

9. Xu Y, Schneier F, Heimberg RG, Princisvalle K, Liebowitz MR, Wang S, et al.: Gender differences in social anxiety disorder: Results from the national epidemiologic sample on alcohol and related conditions. J Anxiety Disord. 2012, 26:12-19.

10. Turk CL, Heimberg RG, Orsillo SM, Holt CS, Gitow A, Street LL, et al: An investigation of gender differences in social phobia. J Anxiety Disord. 1998, 12:209-23.

11. Taylor S: Meta-analysis of cognitive-behavioral treatments for social phobia . J Behav Ther Exp Psychiatr. 1996, 27:1-9.

12. Fedoroff IC, Taylor S: Psychological and pharmacological treatment of social phobia: meta analysis. J Clin Psychopharmacol . 2001, 21:311-24.

13. Kessler RC, Berglund P, Demler O, Jin R, Merikangas KR, Walters EE: Lifetime prevalence and age-of-onset distributions of DSM-IV disorders in the National Comorbidity Survey Replication. Arch Gen Psychiatry. 2005, 62:593-602.

14. Magee WJ, Eaton WW, Wittchen HU, McGonagle KA, Kessler RC: Agoraphobia, simple phobia, and social phobia in the national Comorbidity Survey. Arch Gen Psychiatry. 1996, 53:159-68.

15. DuPont RL, DuPont CM, Rice DP: Economic costs of anxiety disorders. Textbook of Anxiety Disorders. Edited by Stein DJ, Hollander E (ed): American Psychiatric Publishing, Washington, DC; 2002. 475-83.

16. Verhaak PF, Schellevis FG, Nuijen J, Volkers AC: Patients with a psychiatric disorder in general practice: determinants of general practitioners' psychological diagnosis. Gen Hosp Psychiatry. 2006, 28:125-32.

17. Young AS, Klap R, Sherbourne CD, Wells KB: The quality of care for depressive and anxiety disorders in the United States. Arch Gen Psychiatry. 2001, 58:55-61.

18. Lecrubier Y: Comorbidity in social anxiety disorder: impact on disease burden and management. J Clin Psychiatry. 1998, 59:33-38.

19. Ranta K, Kaltiala-Heino R, Rantanen P, Tuomisto MT, Marttunen M: Screening social phobia in adolescents from general population: The validity of the Social Phobia Inventory (SPIN) against a clinical interview. Eur Psychiatry . 2007, 244-51.

20. Connor KM, Davidson JRT, Churchill LE, Sherwood A, Foa E, Weisler RH: Psychometric properties of the Social Phobia Inventory (SPIN): new self-rating scale. Br J Psychiatry. 2000, 176:379-86.

21. Ranta K, Kaltiala-Heino R, Rantanen P, Marttunen M: The Mini-Social Phobia Inventory: psychometric properties in an adolescent general population sample. Compr Psychiatry. 2012, 53:630-37.

22. Turner SM, Beidel DC, Dancu CV: SPAI: Social phobia and anxiety inventory. Multi-Health system Inc., New York; 2004.

23. Baños RM, Botella C, Quero S, Medina P: The social phobia and anxiety inventory: psychometric properties in a Spanish sample. Psychol Rep. 2007, 100:441-50.

24. Picon P, Gauer GJ, Hirakata VN, Haggsträm LM, Beidel DC, Turner SM, et al: Reliability of the Social Phobia and Anxiety Inventory (SPAI) Portuguese version in a heterogeneous sample of Brazilian university students. Rev Bras Psiquiatr. 2005, 27:124-30.

25. Peters L: Discriminant validity of the Social Phobia and Anxiety Inventory (SPAI), the Social Phobia Scale (SPS) and the Social Interaction Anxiety Scale (SIAS). Beha Res Ther . 2000, 38:943-50.

26. Rodebaugh TL, Chambless DL, Terrill DR, Floyd M, Uhde T: Convergent, discriminant, and criterion-related validity of the Social Phobia and Anxiety Inventory. Depress Anxiety. 2000, 11:10-14.

27. Bögels SM \& Reith W: Validity of Two Questionnaires to Assess Social Fears: The Dutch Social Phobia and Anxiety Inventory and the Blushing, Trembling and Sweating Questionnaire.. J 
Psychopathol Behav Assess . 1999, 21:51-66.

28. Cox BJ, Ross L, Swinson RP, Direnfeld DM: A comparison of social phobia outcome measures in cognitive-behavioral group therapy. Behav Modif . 1998, 22:285-97.

29. Inglés CJ, Piqueras JA, García-Fernández JM, García-López LJ, Delgado B, Ruiz-Esteban C: Gender and age differences in the cognitive, psychophysiological, and behavioral responses of social anxiety in adolescence. Psicothema . 2010, 22:376-81.

30. Beidel DC, Turner SM, Cooley MR: Assessing reliable and clinically significant change in social phobia: validity of the social phobia and anxiety inventory. Behav Res Ther. 1993, 31:331-37.

31. Beidel DC, Borden JW, Turner SM, Jacob RG: The Social Phobia and Anxiety Inventory: concurrent validity with a clinic sample. Behav Res Ther. 1998, 27:573-76.

32. Leary MR: A brief version of the Fear of Negative Evaluation Scale. Pers Soc Psychol B. 1983, 9:371-76.

33. Carleton RN, Collimore KC, McCabe RE, Antony MM: Addressing revisions to the brief fear of negative evaluation scale: Measuring fear of negative evaluation across anxiety and mood disorders. J Anxiety Disord. 2011, 25:822-28.

34. Collins KA, Westra H, Dozois DJA, Stewart SH: The validity of the brief version Of the Fear of Negative Evaluation Scale. J Anxiety Disord . 2005, 19:345-59.

35. Duke D, Krishnan M, Faith M, Storch EA: The psychometric properties of the brief negative evaluation scale. J Anxiety Disord. 2006, 20:807-17.

36. Gallego MJ, Botella C, Quero S, Banos RM, Garcia-Palocious A: Propiedades psicometricas de la Escala de Miedo a la Evaluacion Negativa version breve (BFNE) en muestra clinica. RPPC. 2007, 12:163-76.

37. Koydemir S, Demir A: Psychometric properties of the brief version of the fear of negative evaluation scale in Turkish sample. Psychol Rep. 2007, 100:883-93.

38. Rodebaugh TL, Woods CM, Thissen DM, Heimberg RG, Chambless DL, Rapee RM: More information from fewer questions: the factor structure and item properties of the original and brief Fear of Negative Evaluation scale. Psychol Assessment . 2004, 16:169-81.

39. Rodebaugh, TL, Heimberg RG, Brown PJ, Fernandez KC, Blanco C, Schneier FR, Liebowitz MR: More reasons to be straightforward: Findings and norms for two scales relevant to social anxiety. J Anxiety Disord. 2011, 25:623-30.

40. Schützler L, Carleton RN, Witt CM: The Illness/Injury Sensitivity Index: Validation of a German Version of the ISI-R. Cogn Behav Ther. 2012, 41:223-29.

41. Shirotsuki K, Sasagawa S, Nomura S: How do the cost bias and probability bias influence social anxiety symptoms?. Shinrigaku Kenkyu . 2010, 81:381-87.

42. Tavoli A, Melyani M, Bakhtiari M, Ghaedi GH, Montazeri A: The Brief Fear of Negative Evaluation Scale (BFNE): translation and validation study of the Iranian version. BMC Psychiatry. 2009, 9:42.

43. Weeks JW, Heimberg RG, Fresco DM, Hart TA, Turk CL, Schneier FR, Liebowitz MR: Empirical validation and psychometric evaluation of the Brief Fear of Negative Evaluation Scale in patients with social anxiety disorder. Psychol Assess. 2005, 17:179-90.

44. Vassilopoulos SP, Watkins ER: Adaptive and maladaptive self-focus: a pilot extension study with individuals high and low in fear of negative evaluation. Behav Ther. 2009, 40:181-89.

45. Zang YL, Chung LYF, Wong TKS, Chan MF: Female nurses' sensitivity to male genitaliarelated care in mainland China. JCN. 2012, 21:522-34.

46. Kuusikko S, Pollock-Wurman R, Ebeling H, Hurtig T, Joskitt L, Mattila ML, et al: Psychometric evaluation of social phobia and anxiety inventory for children (SPAI-C) and social anxiety scale for children-revised (SASC-R). Eur Child Adolesc Psychiatry. 2009, 18:116-24.

47. Cohen J: Statistical power analysis for the behavior sciences (2nd ed.). Lawrence Erlbaum Associates Inc., NJ; 1988.

48. Gallego Pitarch MJ: Brief version of the fear of negative evaluation scale -straightforward items (BFNE-S): Psychometric properties in a Spanish population. Span J Psychol. 2010, 13:981-89.

49. Koydemir S, Demir A: Shyness and cognitions: an examination of Turkish university students . J Psychol. 2008, 142:633-44.

50. Ranta K, Junttila N, Laakkonen E, Uhmavaara A, La Greca AM, Niemi PM: Social Anxiety Scale for Adolescents (SAS-A): Measuring Social Anxiety Among Finnish Adolescents. Child Psychiatry Hum Dev . 2012, 43:574-91. 
51. Cairney J, McCabe L, Veldhuizen S, Corna LM, Streiner D, Herrmann N: Epidemiology of social phobia in later life. Am J Geriatr Psychiatry. 2007, 15:224-33.

52. Ries BJ, McNeil DW, Boone ML, Turk CL, Carter LE, Heimberg RG: Assessment of contemporary social phobia verbal report instruments. Behav Res Ther. 1998, 36:983-94.

53. Ranta K, Kaltiala-Heino R, Rantanen P, Marttunen M: Social phobia in Finnish general adolescent population: prevalence, comorbidity, individual and family correlates, and service use. Depress Anxiety . 2009, 26:528-36.

54. Pirkola S, Isometsa E, Suvisaari J, Aro H, Joukamaa M, Poikolainen K, et al.: DSM-IV Mood-, anxiety- and alcohol use disorders and their comorbidity in the Finnish general population: results from the Health 2000 Study. Soc Psychiatry Psychiatr Epidemio. 2005, 40:1-10.

55. Wittchen HU, Lachner G, Wunderlich U, Pfister H: Test-retest reliability of the computerized DSM-IV version of the Munich-Composite International Diagnostic Interview (M-CIDI). Soc Psychiatry Psychiatr Epidemiol. 1998, 33:568-78.

56. Kessler RC, Chiu WT, Jin R, Ruscio AM, Shear K, Walters EE: The epidemiology of panic attacks, panic disorder, and agoraphobia in the National Comorbidity Survey Replication. Arch Gen Psychiatry. 2006, 63:415-24.

57. Davidson JRT, Hughes DL, George LK, Blazer DG: The epidemiology of social phobia: Findings from the Duke Epidemiological Catchment Area Study. Psychol Med. 1993, 23:709-18.

58. Clark DM \& Wells A: A cognitive model of social phobia. In Social phobia: diagnosis, assessment, and treatment. Heimberg RG, Liebowitz M, Hope D, Scheier F (ed): Guilford; New York; 1995.

59. Beck AT, Emery G, Greenberg L: Anxiety disorders and phobias: a cognitive perspective . Guilford, New York; 1985.

60. Hartman LM: A metacognitive model of social anxiety: implications for treatment . Clin Psychol Rev . 1983, 3:435-56.

61. Rapee RM \& Heimberg RG: A cognitive-behavioral model of social anxiety in social phobia . Behav Res Ther. 1997, 35:741-56.

62. Schlenker BR \& Leary MR: Social anxiety and self-presentation: a conseptualization model . Psychol Bull. 1982, 92:641-69.

63. Haapsamo H, Pollock-Wurman R, Kuusikko-Gauffin S, Ebeling H, Larinen K, Soini H, Moilanen I: Maternal stress and young children's behavioural development. A prospective pilot study from 8 to 36 months in a Finnish sample. GECD. In press. 